\title{
Continuing a pregnancy after diagnosis of a lethal foetal abnormality: views and perspectives of Australian health professionals and parents
}

Alice WEEKS, Master of Genetic Counselling Student, Department of Paediatrics, University of Melbourne, Grattan St, Parkville VIC 3052, alice.weeks1@gmail.com

Sibel SAYA, Master of Genetic Counselling Student, Department of Paediatrics, University of Melbourne, Grattan St, Parkville VIC 3052, sibel.saya@unimelb.edu.au

Corresponding author:

Associate Professor Jan HODGSON, Research Coordinator, Department of Paediatrics, University of Melbourne, Grattan St, Parkville VIC 3052, and Genetics Education and Health Research, Murdoch Childrens Research Institute, 50 Flemington Rd, Parkville 3052 VIC T: +61 39345 4936, hodgson@unimelb.edu.au, https://orcid.org/0000-0001-7821-9617

Short title: Experience and views on perinatal palliative care

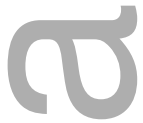

Acknowledgements: The authors wish to acknowledge Ms Shauna Buscombe for her assistance with the projects. The authors also wish to acknowledge with gratitude the participants, and to thank organisations which assisted in recruitment. Assistance with recruitment was provided by SIDS and Kids, SANDS, Very Special Kids, The Teddy Love Club, and Trisomy Oz. We would also like to thank reviewers for their helpful comments.

This research was carried out in partial fulfilment of Alice Weeks's and Sibel Saya's Master of Genetic Counselling, Department of Paediatrics, University of Melbourne and was supported by the Victorian Government's Operational Infrastructure Support Program. The authors declare no conflicts of interest.

Footnote: AW present affiliation: Genetic Counsellor, Number 1 Fertility, Melbourne VIC 3000

SS present affiliation: PhD Candidate, Centre for Cancer Research, Department of General Practice, Victorian Comprehensive Cancer Centre, The University of Melbourne, Grattan St, Parkville VIC 3052

This is the author manuscript accepted for publication and has undergone full peer review but has not been through the copyediting, typesetting, pagination and proofreading process, which may lead to differences between this version and the Version of Record. Please cite this article as doi: $10.1111 /$ AJO.13157

This article is protected by copyright. All rights reserved 
JH present affiliation: Program Director, Master of Genetic Counselling and Master of Genomics and Health, Department of Paediatrics, Melbourne Medical School, Royal Children's Hospital, The University of Melbourne, Parkville VIC 3052

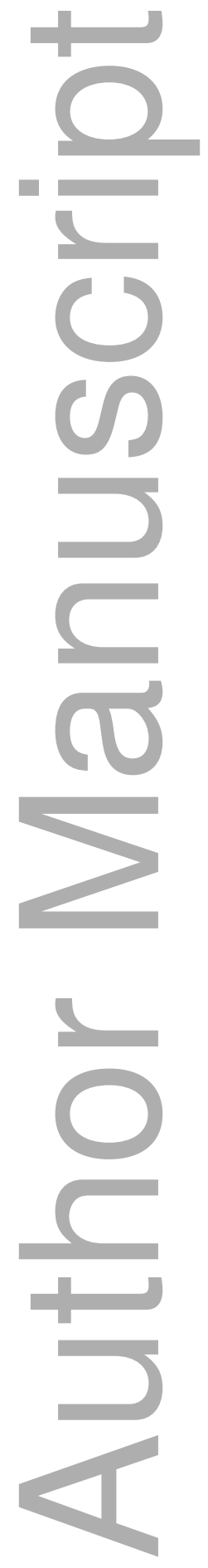


MS. ALICE WEEKS (Orcid ID : 0000-0001-8485-4529)

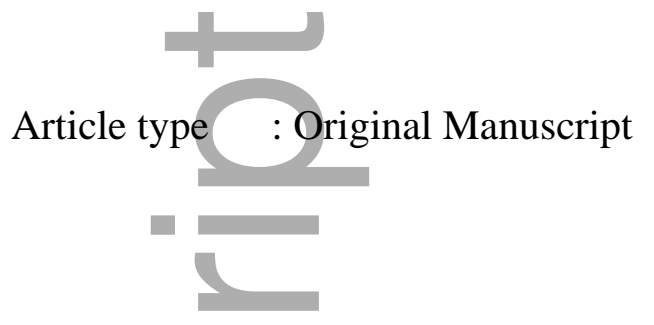

Title: Continuing a pregnancy after diagnosis of a lethal foetal abnormality: views and perspectives of Australian health professionals and parents.

\begin{abstract}
:
Background: Couples who receive a prenatal diagnosis of a foetal anomaly in Victoria,
\end{abstract} Australia are generally offered a choice about whether or not to continue with the pregnancy. When a severe or 'lethal' abnormality is diagnosed some couples decide to continue the pregnancy in the knowledge that their baby may die before or shortly after birth. Several Australian parents who published personal accounts of that experience describe a lack of clear clinical pathways, suggesting those who decide to continue a pregnancy following a diagnosis of a 'lethal foetal abnormality' (LFA) may not be receiving optimal care.

Aims: This study aimed to provide empirical Australian evidence of views and experiences of care provision from health professionals (HPs) and parents.

Materials and Methods: Two sequential phases of this qualitative study purposively recruited a range of key HPs and parents. Semi-structured interviews were thematically analysed. Results: Findings reveal that current care provision following prenatal diagnosis of an LFA is 'ad hoc' with both participant groups identifying disparities between parents' needs and available care. However, the goodwill and good intentions of all HPs involved was apparent. There was strong support from both groups for considering a model of perinatal palliative care (PPC) based on existing programs overseas.

Conclusions: Future care provision in this setting needs to be redefined. A formal PPC program could ensure better and more consistent experiences of support for parents as well as the HPs working in the field. 


\section{Introduction}

Prenatal testing is increasingly a routine part of pregnancy care ${ }^{1}$. Screening and diagnostic tests identify a wide range of foetal abnormalities including chromosomal abnormalities such as Down syndrome and structural anomalies such as heart defects. Most recently adoption of non-invasive prenatal testing (NIPT) is resulting in an increased number of chromosomal abnormalities diagnosed in the prenatal period ${ }^{2,3}$.

When a 'lethal foetal abnormality' (LFA) is diagnosed prenatally, women are usually offered a choice between continuing the pregnancy, knowing that their baby will most likely die before or shortly after birth, or terminating the pregnancy. To ensure parents can make an informed choice it is crucial to provide access to health professionals (HPs) who can support them appropriately and provide accurate information. Despite several 'lethal' conditions being considered 'incompatible with life', babies may survive for a period after birth ${ }^{4}$.

Care offered to parents who continue their pregnancy in these circumstances varies between different settings and geographical location. Over the past two decades, formal programs of perinatal palliative care (PPC) have developed internationally with some published models of PPC from centres in USA and Europe ${ }^{5-10}$.

In Australia, the majority of couples choose to terminate their pregnancy in this situation ${ }^{11}$ and care plans for this path are generally well-established. For those who do not want to terminate their pregnancy, the process is less clear. It is possible that an alternative process would be welcomed by some. Within the Australian context, little is known about how parents experience a diagnosis of an LFA. Individual case studies/anecdotal accounts provide evidence that care experienced by Australian parents and babies in these circumstances is sometimes less than optimal ${ }^{12,13}$. Perinatal loss websites (e.g. Bears of Hope ${ }^{14}$ ) report parents feeling unsupported by HPs in their choice to continue their pregnancy. Personal accounts of those who choose to continue ${ }^{12,13}$ describe some inadequacies in the care provided ${ }^{15}$, with no further published Australian research. There have been calls for further investigation into parents' and clinicians' views and experiences of $\mathrm{PPC}^{5,6}$.

The two sequential study phases described here provide perspectives from Australian HPs and parents regarding care and support when continuing a pregnancy following prenatal diagnosis of an LFA. 


\section{Materials and Methods}

The studies aimed to explore HP and parents views and experiences of care surrounding continuation of pregnancy following diagnosis of an LFA. A qualitative approach using a phenomenological theoretical framework ${ }^{16,17}$ was taken. Review of published PPC models and literature ${ }^{18-26}$ by AW led to identification of consistent concepts, presented as key care concepts (Table 1). These concepts, validated by an international PPC professional Special Interest Group, were used to direct and focus the research questions.

Phase 1 of the study aimed to explore current practice of care for women in Victoria who choose to continue a pregnancy following diagnosis of an LFA.

Phase 2 of the study aimed to explore parents' experiences of continuing a pregnancy following diagnosis of an LFA, specifically care and support they received and services they found useful. Suggestions for future care of families were also explored. Within both phases, participants were asked their views on the PPC key care concepts.

Both phases received institute specific ethics approval (University of Melbourne Human Research Ethics Committee; Phase 1: 0830822; Phase 2: 0932781).

\section{Sampling and recruitment}

Phase 1, 'Key informant HPs' in Victoria were purposively sampled, identified through the authors' professional networks, with the aim of providing a broad range of views from relevant $\mathrm{HPs}^{27}$. All had been involved in caring for women who chose to continue a pregnancy diagnosed with an LFA. Prospective participants were directly approached via email; all HPs invited to participate in the study accepted the offer.

Phase 2, parents in Victoria who had received a diagnosis of an LFA during pregnancy more than twelve months previously were identified through advertisements in newsletters of perinatal loss support groups and through HPs at a tertiary obstetric centre in Melbourne, Australia. Interested parents were invited to contact the researchers for further information. Written informed consent was obtained from all participants.

\section{Data collection}

Semi-structured qualitative interviews provided the best means of obtaining the depth of information being sought. Given the sensitivity of the topic, parent couples who wanted to 
participate were given the option to be interviewed together or separately. Interviews were performed face-to-face by AW (phase 1) and SS (phase 2) at a mutually convenient location, digitally audio-taped and transcribed verbatim. Transcripts were de-identified and pseudonyms assigned.

Given the exploratory nature of this study, structured interview guides were not used, rather the domains of interest for interviews included participants' experience of current care, and their views on positive and negative aspects of care. All participants were asked their views on a model of PPC care based on the key care concepts.

\section{Data analysis}

Thematic analysis was used to analyse interview data ${ }^{17}$. The analytical process involved AW (phase 1) and SS (phase 2) thematically coding transcripts as well as co-coding by coauthors. This provided validation of themes that arose inductively from each of the coded transcripts.

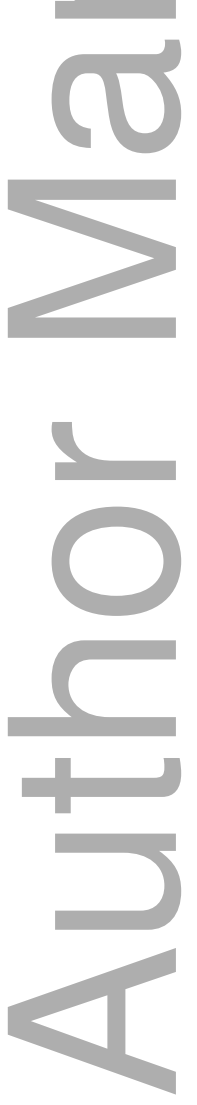




\section{Results}

Interviews were conducted between March 2009 and September 2010 with eight key informant HPs (phase 1) and with eleven parents (from seven parent couples, phase 2; Table 2). One couple chose to be interviewed together. Interviews ranged from 30 to 90 minutes in length in phase 1 and from 40 to 120 minutes in phase 2.

Separate thematic analyses identified a large number of themes in each phase, which are not explored in this paper. Themes from phase 1 included: the ad hoc nature of current care; the professional and personally challenging areas of care; that the term 'LFA' is inadequate and inaccurate; and the importance of hope and good intentions of HPs. Phase 2 themes included: uncertainty about the babies' outcomes; the importance of hope for parents and respect from HPs; and grief for the loss of their baby. There was consensus across both phases on many findings, of which the three key findings are described below: that current care is 'ad hoc'; consistent support for PPC key care concepts; and existence of goodwill and good intentions. These findings are presented below along with illustrative quotes (Table 3).

\section{Key finding 1: Current care is 'ad hoc'}

\section{Variable and Flexible Care}

Overall, HPs described care as variable, deliberately flexible and sometimes managed inconsistently (Q1).

Parents echoed HPs views, reporting variable experiences that some described as a "rollercoaster ride". The main theme emerging from both participant groups was that care often appeared 'ad hoc'. Although seen by some as a negative aspect, others recognised the 'ad hoc' nature reflected the need for flexibility in order to provide individualised support. HPs and parents alike described variability in care as being influenced by the specifics of diagnosis and prognosis, the setting and need for specific management of maternal medical issues during pregnancy.

HPs also explained that close medical management was required for couples who wanted to maximise the chance of their baby being born alive.

\section{Planning}

While it was clear from parents who were interviewed that there were no formal programs/guidelines available at the time, there had generally been attempts to develop a 
custom-made plan for them. This was difficult to think about, but future planning was deemed important for emotional preparedness and to manage uncertainty. Parents highlighted a desire for flexibility as new prognostic information about their baby's condition became available. While parents wanted to play an active role in planning for the birth and death of their baby, intense emotions and grief made this challenging with many reporting relying heavily on expertise of staff to guide and support them through the process (Q2). Parents greatly appreciated experts being on-hand to provide this support.

\section{Communication, uncertainty and terminology}

The paramount importance of clear and sensitive communication for parents was evident, particularly at the time of diagnosis and when talking about whether or not to terminate the pregnancy. Parents appreciated a non-directive approach, which helped them feel supported in their decisions (Q3) and many described how sensitive and realistic communication about their baby's prognosis positively impacted their feelings of hope and uncertainty.

Parents commonly felt very uncertain about what path their baby's life might take (Q4). HPs highlighted that the variable and changing nature of LFAs meant that while parents understood that HPs could never be certain about what might happen, they appreciated clear and open communication about possibilities.

HPs highlighted the inaccuracy and inadequacy of the term 'lethal foetal abnormality' to capture often complex and unpredictable disease courses. HPs instead favoured an open discussion about prognosis and estimated chances of survival over different timeframes (Q5 \& Q6).

\section{Professional challenges - 'Turf war'}

Some HPs spoke about professional challenges associated with being part of a multidisciplinary team, and in particular 'crossover' of roles between HPs within the team. Some described a sense of 'ownership' of patients or feeling caught up in a 'turf war' between HPs. The uncertainty about roles of team members sometimes appeared to stem from lack of clarity about the primary contact person (Q7), often as a result of role crossover between the HPs.

\section{Key finding 2: Consistent support for PPC key care concepts}

Parents and HPs alike were highly supportive of inclusion of the concepts of PPC in a model of care. Both groups envisaged specific challenges in implementation of a formal model of 
PPC. HPs specifically highlighted concerns about variability and the 'ad hoc' nature of care provision which is dependent on available financial, time and personnel resources.

Parents emphasised the need for a collaborative team approach that includes all relevant specialities, with themselves central to all discussions and decision making (Q8 \& Q9). Many HPs indicated that implementation of a formal PPC program would require specific institutional recognition and prioritisation for staff and patients of this type of care during pregnancy (Q10).

HPs identified the need for professional training for everyone involved in pregnancies diagnosed with an LFA. They also highlighted provision of emotional support for HPs as another important, yet often overlooked, component of providing holistic PPC.

Some parents suggested adding peer support to the model, with parents who had experienced pregnancy diagnosed with an LFA providing support to other families.

\section{Key finding 3: Existence of goodwill and good intentions}

Although working in this area was uniquely challenging for HPs, they considered providing families with understanding and sensitivity before and after the birth or death of their child to be an important role (Q11).

'Maintaining hope' was important for both HPs and parents (Q13). For many parents, the uncertainty of their baby's prognosis allowed them to feel hopeful that their baby would survive (Q12 \& Q13).

Parents reported wanting to maximise time with their baby. For some, HP support to bathe or dress their baby helped them feel like a 'normal' parent (Q14). Overall, parents characterised time spent after birth while their baby was alive, and again after their baby's death, as 'irreplaceable'. When HPs showed they understood the significance of this time, it was appreciated and parents felt they and their baby were respected (Q16).

HPs reported determination to provide the best support possible in these circumstances (Q15) and both groups felt that HPs were doing their best given the current system of care and available resources. Parents consistently described being treated with kindness and respect, showcasing the parent experience of HPs' desire and efforts to provide sensitive and wellrounded care to families (Q16 \& Q17). 


\section{Discussion}

Although the last 10 years has seen significant advances in the scope and accessibility of prenatal testing, PPC programs remain unavailable to most Australians and we consider the relevance of our findings to be more important now than ever.

The findings demonstrate important implications for practice. Current care is 'ad hoc', variable and flexible, with both parents and HPs describing the complex medical and psychosocial support needs following a diagnosis of an LFA. Support for a PPC model providing personalised care was underpinned by the strong feelings of goodwill by parents and HPs alike.

The theme of 'turf wars' in this research was unexpected and often challenging for HPs to discuss. Crossover of roles and perceptions of ownership, while raising some professional difficulties and possibly contributing to parents' impressions of 'ad hoc' care, stemmed from HPs' desire to provide best possible care. This challenge may not be limited to HPs working with this group of patients ${ }^{28}$ and could be addressed more openly with acknowledgement that it originates from good intentions.

The language HPs used when talking with parents needed to be informative and accurate but also respectful. Consistent with international literature, a particular concern was that describing prenatally diagnosed conditions as 'lethal' is inaccurate in some cases, such as trisomy $18^{29}$. Inherent prognostic uncertainty for some conditions encompassed in the term LFA makes definitive predictions difficult. Frank but sensitive discussions are needed to ensure that parents can make fully informed decisions during pregnancy.

Despite resource constraints, HP willingness to provide comprehensive and sensitive care to parents was evident. These findings, consistent with the literature, demonstrate that holistic patient centred care, with unconditional respect for parents' choices, provides a more positive experience for both HPs and parents ${ }^{6,30-33}$.

Given the sensitive and ethically challenging nature of practice in this area, a formal model of care (PPC), was universally supported by participants. PPC programs provide parents with clinical care and support from prenatal diagnosis of an LFA throughout the pregnancy, including the birth and death of the baby, and beyond ${ }^{6,19,34}$. This is not, as the name implies, a physical building or hospice but rather a model of coordinated care that encompasses home, hospital and the community and is "based on the hospice philosophy of living life fully and enjoying each moment" ${ }^{\text {19, } 22}$. 
PPC teams generally comprise medical and allied HPs including the family physician, obstetrician, social worker and nurse or counsellor coordinator. Neonatologists, anaesthetists, psychologists, chaplains, midwives, neonatal nurses and other specialists are involved as necessary. Proponents of PPC state that programs empower families to take control of their situation, allowing valuable time during pregnancy and after birth for making memories, loving and parenting, impacting positively on subsequent grief processes ${ }^{24}$.

As the concept of PPC originated in USA, changes may need to be made to the model for the local context. However, the successful implementation of PPC in other countries $9,10,35,36$ provides Australian practitioners with useful examples to aid local adoption. Moves to develop such programs have already begun in Australia ${ }^{37,38}$ and the paediatric palliative care model in Victoria has been updated to include perinatal death ${ }^{39}$. A challenge will be to ensure equity of access.

This study provides the first empirical data describing lived experiences of Australian parents who decide to continue a pregnancy after diagnosis of an LFA and their HPs but is not without limitations. Despite the small study sizes, findings provide valuable insights into how parents wish to be cared for at this time.

HPs, purposively sampled for their interest and experience, have likely provided a more informed perspective to the study than many other HPs. This is an important first step which could be followed by broader survey or interview of all HPs working in the area.

Future care provision in this setting may need to be redefined to ensure that parents can make informed and supported choices. A clearly defined protocol of PPC care would provide parents with a tangible, alternative option to consider following diagnosis of an LFA. Implementation of a formal PPC model would enable HPs to provide improved and consistent experiences of care and support for parents.

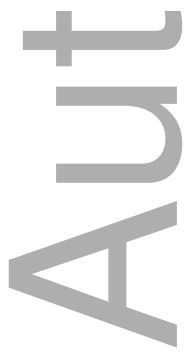




\section{Table legends}

Table 1: Perinatal Palliative Care Key Care Concepts developed from literature review

Table 2: Description of Samples

Table 3: Key findings and illustrative quotes

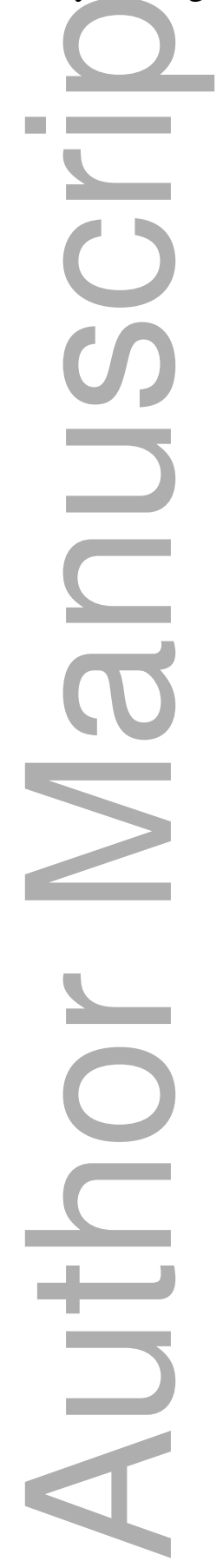

This article is protected by copyright. All rights reserved 


\section{References}

1 Suter SM. Routinization of prenatal testing, the. Am. JL \& Med. 2002; 28: 233.

2 Hui L, Muggli E, Halliday J. Population- based trends in prenatal screening and diagnosis for aneuploidy: a retrospective analysis of 38 years of state- wide data. BJOG: An International Journal of Obstetrics \& Gynaecology. 2016; 123: 90-7.

3 Gil M, Quezada M, Revello R, Akolekar R, Nicolaides K. Analysis of cell- free DNA in maternal blood in screening for fetal aneuploidies: updated meta- analysis.

Ultrasound in obstetrics \& gynecology. 2015; 45: 249-66.

4 Vendola C, Canfield M, Daiger SP, et al. Survival of Texas infants born with trisomies 21, 18, and 13. American Journal of Medical Genetics. Part A. 2010; 152A: 360-6.

5 Balaguer A, Martín-Ancel A, Ortigoza-Escobar D, Escribano J, Argemi J. The model of palliative care in the perinatal setting: a review of the literature. BMC pediatrics. 2012; 12: 25 .

6 Wool C. State of the science on perinatal palliative care. Journal of Obstetric, Gynecologic, \& Neonatal Nursing. 2013; 42: 372-82.

7 De Rooy L, Aladangady N, Aidoo E. Palliative care for the newborn in the United Kingdom. Early human development. 2012; 88: 73-7.

8 Tosello B, Dany L, Betremieux P, et al. Barriers in referring neonatal patients to perinatal palliative care: a French multicenter survey. PLoS One. 2015; 10: e0126861.

9 McMahon DL, Twomey M, O'reilly M, Devins M. Referrals to a perinatal specialist palliative care consult service in Ireland, 2012-2015. Archives of Disease in Childhood-Fetal and Neonatal Edition. 2018; 103: F573-F6.

10 Cavicchiolo ME, Rusalen F, Benini F, Baraldi E, Lago P. Perinatal palliative care: a national survey in Italy. Archives of disease in childhood. Fetal and neonatal edition. 2019; 104: F567.

11 Wilkinson D, de Crespigny L, Xafis V. Ethical language and decision-making for prenatally diagnosed lethal malformations. Semin Fetal Neonatal Med. 2014; 19: 30611.

12 Sheffield K, Not Compatible with Life: A Diary of Keeping Daniel: Best Legenz; 2008.

13 Thiele P. He was my son, not a dying baby. Journal of Medical Ethics. 2010; 36: 646-7.

14 Bears of Hope. Bears of Hope: Pregnancy and Infant Loss Support; 2016. 
15 Wilkinson D, Thiele P, Watkins A, De Crespigny L. Fatally flawed? A review and ethical analysis of lethal congenital malformations. BJOG: An International Journal of Obstetrics \& Gynaecology. 2012; 119: 1302-8.

16 Charmaz K, Constructing grounded theory: A practical guide through qualitative analysis: sage; 2006.

17 Liamputtong P, Ezzy D, Qualitative Research Methods Melbourne, Australia: Oxford University Press; 2005.

18 Roush A, Sullivan P, Cooper R, McBride JW. Perinatal Hospice. Newborn and Infant Nursing Reviews. 2007; 7: 216-21.

19 Ramer-Chrastek J, Thygeson MV. A perinatal hospice for an unborn child with a lifelimiting condition. International Journal of Palliative Nursing. 2005; 11: 274-6.

20 Munson D, Leuthner SR. Palliative care for the family carrying a fetus with a life-limiting diagnosis. Pediatric Clinics of North America. 2007; 54: 787-98, xii.

21 Leuthner SR, Jones EL. Fetal Concerns Program: a model for perinatal palliative care. MCN, American Journal of Maternal and Child Nursing. 2007; 32: 272-8.

22 Leuthner SR. Palliative care of the infant with lethal anomalies. Pediatric Clinics of North America. 2004; 51: 747-59.

23 Leuthner SR. Fetal palliative care. Clinics in Perinatology. 2004; 31: 649-65.

24 Hoeldtke NJ, Calhoun BC. Perinatal hospice. American Journal of Obstetrics and Gynecology. 2001; 185: 525-9.

25 D'Almeida M, Hume RF, Lathrop A, Njoku A, Calhoun BC. Perinatal hospice: familycentered care of the fetus with a lethal condition. Journal of American Physicians \& Surgeons. 2006; 11: 52-5.

26 Breeze ACG, Lees CC, Kumar A, Missfelder-Lobos HH, Murdoch EM. Palliative care for prenatally diagnosed lethal fetal abnormality. Archives of Disease in Childhood. Fetal and Neonatal Edition. 2007; 92: F56-8.

27 Marshall MN. The key informant technique. Family practice. 1996; 13: 92-7.

28 Taylor J, Aldridge J. Exploring the rewards and challenges of paediatric palliative care work - a qualitative study of a multi-disciplinary children's hospice care team. BMC palliative care. 2017; 16: 73.

29 Tosello B, Dany L. Psycho-social approach of perinatal palliative care. The Journal of Maternal-Fetal \& Neonatal Medicine. 2019; 32: 3693-6. 
30 Wool C, Côté-Arsenault D, Perry Black B, Denney-Koelsch E, Kim S, Kavanaugh K. Provision of services in perinatal palliative care: a multicenter survey in the United States. Journal of palliative medicine. 2016; 19: 279-85.

31 Cote-Arsenault D, Denney-Koelsch E. "Have no regrets:" Parents' experiences and developmental tasks in pregnancy with a lethal fetal diagnosis. Soc Sci Med. 2016; 154: 100-9.

32 Denney-Koelsch EM, Côté-Arsenault D, Jenkins Hall W. Feeling Cared For Versus Experiencing Added Burden: Parents' Interactions With Health-Care Providers in Pregnancy With a Lethal Fetal Diagnosis. Illness, Crisis \& Loss. 2018; 26: 293-315.

33 Stenekes S, Penner JL, Harlos M, et al. Development and implementation of a survey to assess health-care provider's competency, attitudes, and knowledge about perinatal palliative care. Journal of palliative care. 2019; 34: 151-9.

34 Engelder S, Davies K, Zeilinger T, Rutledge D. A model program for perinatal palliative services. Advances in Neonatal Care. 2012; 12: 28-36.

35 Rusalen F, Cavicchiolo ME, Lago P, Salvadori S, Benini F. Perinatal palliative care: a dedicated care pathway. BMJ supportive \& palliative care. 2019: bmjspcare-2019001849

36 Guimarães DPG, Areias MHFGP, de Almeida Ramalho CM, Rodrigues MM. Perinatal palliative care following prenatal diagnosis of severe fetal anomaly: a new familycentered approach in a level III Portuguese hospital. Journal of Pediatric and Neonatal Individualized Medicine (JPNIM). 2018; 8: e080102.

37 Mercy Perinatal, Mercy Health. STAR clinic. Vol. 2019; 2019.

38 Jennings B, Criddle S, Dickinson J, Gill A, Warner T. Perinatal Palliative Care Model of Care: a Western Australian initiative. Women and Birth. 2018; 31: S53.

39 Safer Care Victoria, Victorian Agency of Health Information. Palliative (end of life) neonatal carre. Vol. 2019; 2019.

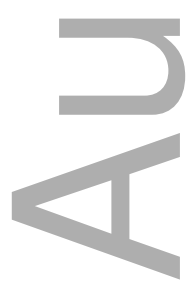


Table 1: Perinatal Palliative Care Key Care Concepts developed from literature review ${ }^{18-26}$

\begin{tabular}{|rl|}
\hline Perinatal Palliative Care - Key Care Concepts \\
\hline 1. & $\begin{array}{l}\text { Providing a supportive environment within which families can engage with and value } \\
\text { whatever time they have with their baby }\end{array}$ \\
\hline 2. & Multidisciplinary team approach to planning and care \\
\hline 3. & Promoting choice for families about each aspect of their care \\
\hline 4. & Personalised spiritual care \\
\hline 5. & Establishing and supporting links between hospital and local community resources \\
\hline
\end{tabular}

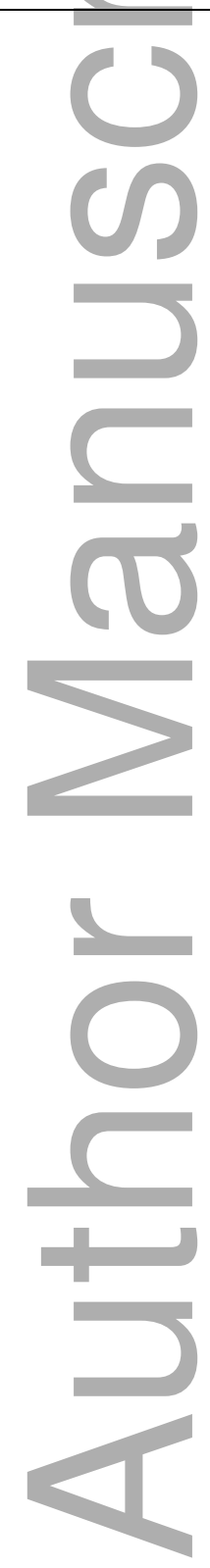


Table 2: Description of Samples

\begin{tabular}{|c|c|}
\hline Health Professionals & $\mathbf{n}$ \\
\hline Clinical Geneticist & 1 \\
\hline Clinical Psychologist & 1 \\
\hline Genetic Counsellor & 1 \\
\hline Neonatologist & 1 \\
\hline $\begin{array}{l}\text { Obstetrician (Maternal Foetal } \\
\text { Medicine) }\end{array}$ & 1 \\
\hline Paediatrician & 1 \\
\hline Palliative Care Worker & 1 \\
\hline Ultrasonologist & 1 \\
\hline Parents & n (parents) \\
\hline Mothers & 7 \\
\hline Fathers & 4 \\
\hline Time since experience & $\mathrm{n}$ (families) \\
\hline $12-24$ months & 4 \\
\hline $2-5$ years & 2 \\
\hline 5+years & 1 \\
\hline Length of baby's life & $\mathrm{n}$ (families) \\
\hline Miscarriage before birth & 1 \\
\hline$<1$ hour & 2 \\
\hline $1-24 \mathrm{hrs}$ & 1 \\
\hline$>1$ day & 3 \\
\hline
\end{tabular}


Table 3: Key findings and illustrative quotes

\begin{tabular}{|c|}
\hline \\
\hline $\begin{array}{l}\text { "It's the less common decision, so the care models, I don't think are as good.....it works out } \\
\text { being a bit 'ad hoc'..... it depends where the woman is being cared for, I think there's an } \\
\text { incredible will on the part of all the teams to provide care, but I think it depends who's leading it, } \\
\text { and how involved they get, and what they do.....it tends to be case by case, and it obviously then } \\
\text { depends on what happens during the pregnancy because we're making these diagnoses often at } \\
12 \text { weeks, the person may not go beyond pregnancy, the baby may die before then..." Q1 (Ash, } \\
\text { health professional) }\end{array}$ \\
\hline $\begin{array}{l}\text { "everything had sort of been done... so... we were sort of presented with a few options and again, } \\
\text { it was done very sensitively..... they sort of said, 'look, you know, if you want to take, take } \\
\text { Elizabeth home, on a ventilator and we'll help you look after her at home with, you know, support } \\
\text { and nursing care and whatever..... look at different things of, different ways of withdrawing } \\
\text { treatment, whether you can do that in hospital um, or you can take her home and do that or'..... } \\
\text { they were... very understanding and ... very sensitive about it..... there was one doctor in } \\
\text { particular who sort of took us under his wing ..... I remember he said to us, that ... he 'll basically } \\
\text { do whatever we want to do as long as he doesn't have to go to jail, and (laughs) so I thought that } \\
\text { was pretty, kind of him and in that he's just open to however we want to ...... spend time with } \\
\text { Elizabeth...." Q2 (Andrew, parent) }\end{array}$ \\
\hline $\begin{array}{l}\text { "[they] gave us the impression that..... they were happy... very supportive.... [about] the step that } \\
\text { we'd taken to, to go ahead with it.... gave us the impression that we were being brave about it..... } \\
\text { they were very supportive..." } \mathbf{Q 3} \text { (James, parent) }\end{array}$ \\
\hline $\begin{array}{l}\text { "I did find different specialities had completely different prognoses..... which was quite confusing } \\
\text { and confronting..... and I remember going to [the hospital]..... with the belief [she] had zero } \\
\text { chance of survival..... and then the surgeon..... automatically went from zero to } 80 \text { percent which } \\
\text { is really difficult to adjust to, and..... [the] obstetrician that day.... said, 'well I don't believe it's } \\
80 \ldots . . \text { at best, it's 50", so we had all these conflicting [opinions]..... which was the most difficult } \\
\text { thing..." Q4 (Gabrielle, parent) }\end{array}$ \\
\hline $\begin{array}{l}\text { "I think it's confusing for couples, and it's labelling their foetus as 'lethal', and they're making } \\
\text { decisions on that, whereas that's incorrect, and they're being deceived, in a sense..." } \mathbf{Q 5} \text { (Jo, } \\
\text { health professional) }\end{array}$ \\
\hline e language...I know that you're trying to capture a certain amount of \\
\hline
\end{tabular}

This article is protected by copyright. All rights reserved 
area is that people expect the babies to die before birth or straight away, but that's not always the case...for the patient, I wouldn't use the term 'lethal foetal abnormality'..." Q6 (Ash, health professional)

"I think there's a real ownership issue over these patients, and that needs to be carefully negotiated because I think... any idea of a hospice sort of implies that there might be something that could be better and that I reckon that makes them defensive.....there is with patients, people feel very possessive over patients, and these patients who are sort of genetics but they're also paediatrics and they're also obstetrics, yeah, they're absolutely, and 'turf wars' happen a lot in medicine, I think..... there is a real territorial thing that happens with doctors thinking they own patients, strange but...I think there's a lack of trust, and they want, that they know that a certain type of care will be delivered, so it's a bit of a control thing, and that, yeah, motivated not just from needing to be important themselves, but also wanting to ensure that things go a certain way..." Q7 (Lee, health professional)

\section{Finding 2: Supportive of Perinatal Palliative Care}

"I think it's important that families have choice... I think it's important that you're in control, and I don't think you can have professionals telling you what, obviously they need to guide you and to some extent..... but you need to feel like you are informed and that you have some sense of control..." Q8 (Gabrielle, parent)

"the team approach..... I couldn't emphasise that enough, if you don't have that team approach, and for the doctors to say..... 'look, I don't know about the question you're posing', or this, 'I'm going to refer it and come back to you', [the obstetrician] being honest and open and up front, I, I really appreciated that..." $\mathbf{Q}$ (Eric, parent)

"All five of these elements are crucial to comprehensive care in this circumstance, but clearly there needs to be an institutional valuing of the fact that a service of this kind should exist within it, and then an engagement with what that actually means, in terms of staff resources and time and place, all of those things.... very much presenting sort of institutional demonstration that they don't just provide a pregnancy termination service, they also [provide] a pregnancy continuation service, in this circumstance, and that would be reflected in a named service, staff resourcing, commitment to research into practice, all of those things.... it would need that sort of institutional endorsement to bring about the improvement in service ..... that that might be the setting in which families really could be given the option of engaging with what does this mean for us..." Q10 (Chris, health professional)

\section{Finding 3: Goodwill}




\begin{tabular}{|c|}
\hline $\begin{array}{l}\text { got a situation that's sort of hopeless in a sense, then the role of the doctors in those situations is, } \\
\text { you know I think that that hopelessness, helplessness can be a bit infectious..." Q11 (Lee, health } \\
\text { professional) }\end{array}$ \\
\hline $\begin{array}{l}\text { "[the obstetrician] was just amazing, he allowed me to hope..... because if you don't have hope in } \\
\text { a pregnancy like that..... you won't cope" Q12 (Kirsten, parent) }\end{array}$ \\
\hline $\begin{array}{l}\text { redibly important..... because there's always that hope that maybe people have } \\
\text { terpreted the tests incorrectly, and they'll be the one in a million where it's } \\
\text { m, health professional) }\end{array}$ \\
\hline $\begin{array}{l}\text { any moments but it was one of those moments where you kind of almost felt } \\
\text { though you're in the NICU, you kind of just block it all out..... well this is us } \\
\text { and you know, having time with our baby..." Q14 (Bernadette, parent) }\end{array}$ \\
\hline $\begin{array}{l}\text { are providing them with support..... I'm sure nobody just says 'see you in } 3 \\
\text { le are doing their very best” Q15 (Sam, health professional) }\end{array}$ \\
\hline $\begin{array}{l}\text { ys very sensitive, treated our child with respect.... that was lovely.... I can't } \\
\text { ly of the way the [hospital] looked after our Chloe, for those two months .....I } \\
\text { loved her, because they all cried when she (voice cracking) passed away, just } \\
\text { ent way beyond the call of duty like, when she passed away, [the funeral } \\
\text { to collect her, they even held her hand (voice cracking) as they walked around } \\
\text { ans a lot..." Q16 (Charlotte, parent) }\end{array}$ \\
\hline $\begin{array}{l}\text { "you could see it, [the neonatologist] was clearly moved himself, he was very teary and I guess, it } \\
\text { was like our family, or Alexandra's family..... they're really the only people who knew her, they, } \\
\text { they were there grieving with us and then [when] she died..... all the workers came in that } \\
\text { morning, it was kind of just like an open house, you know, Alexandra was there, in this beautiful } \\
\text { bassinet that they had made up for her..... the social workers, the pastoral care workers, the } \\
\text { doctors, the nurses, the people who had cared for her..." Q17 (Bernadette, parent) }\end{array}$ \\
\hline ..). $A n e$ \\
\hline
\end{tabular}

This article is protected by copyright. All rights reserved 


\section{University Library}

\section{- M M N E R VA A gateway to Melbourne's research publications}

Minerva Access is the Institutional Repository of The University of Melbourne

Author/s:

Weeks, A;Saya, S;Hodgson, J

Title:

Continuing a pregnancy after diagnosis of a lethal fetal abnormality: Views and perspectives of Australian health professionals and parents

Date:

2020-04-23

\section{Citation:}

Weeks, A., Saya, S. \& Hodgson, J. (2020). Continuing a pregnancy after diagnosis of a lethal fetal abnormality: Views and perspectives of Australian health professionals and parents. AUSTRALIAN \& NEW ZEALAND JOURNAL OF OBSTETRICS \& GYNAECOLOGY, 60 (5), pp.746-752. https://doi.org/10.1111/ajo.13157.

Persistent Link:

http://hdl.handle.net/11343/275676 